\title{
Inferred spatial use by elephants is robust to landscape effects on GPS telemetry
}

\author{
Theresia Ott \& Rudi J. van Aarde* \\ Conservation Ecology Research Unit, Department of Zoology and Entomology, \\ University of Pretoria, Pretoria, 0002 South Africa \\ Received 20 August 2009. Accepted 24 June 2010
}

\begin{abstract}
Global Positioning System (GPS) telemetry provides data to study spatial utilization patterns of animals. Spatial uncertainty due to poor accuracy and fix rates, however, may detract from inferences based on such data. The exclusion of two-dimensional (2D) locations may improve such inferences, but the prevalence of 2D locations may be a factor of landscape properties. In trials conducted using GPS units stationed at known positions, fix rate decreased significantly with increased canopy cover, but was unaffected by slope. Most $(75 \%)$ of the locations recorded in closed woodland were 2D locations, suggesting that the exclusion of 2D locations may reduce estimates of the utilization of such habitats. Excluding 2D locations from records obtained for GPS units deployed on free-ranging elephants (Loxodonta africana) increased daily displacement distances, and changed the number of locations per habitat. However, selection ratios and estimates of home range area were not influenced by filtering location data. We concluded that although the exclusion of 2D locations improved the accuracy of locations per se, it resulted in significant data loss. This loss could alter inferences on patterns of spatial utilization.
\end{abstract}

Key words: elephant, fix rate, GPS, location accuracy, satellite tracking, telemetry.

\section{INTRODUCTION}

The accuracy of locations returned by Global Positioning Systems (GPS) deployed on animals relies on the performance of GPS devices. Performance depends on landscape properties that interfere with communication between the device and GPS satellites (Lewis et al. 2007). Fix rate and location accuracy are two ways to express the performance of these units. Fix rate refers to the proportion of locations a GPS unit calculated, to those attempted (Moen et al. 1996). Location accuracy is usually dependent on whether a two- (2D) or three-dimensional (3D) location is calculated (Moen et al. 1997). The availability of four or more satellites allows for 3D location calculations, whilst the less accurate 2D locations are calculated when only three satellites are available (Moen et al. 1996). With open-sky conditions, more than five GPS satellites should be available most ( $>99 \%$ ) of the time (US Department of Defence, as cited by Moen et al. 1997), suggesting that poor satellite acquisition and thus more $2 \mathrm{D}$ locations, must be due to the properties of the landscapes where animals are tracked (Moen et al. 1997).

Indeed, fix rate and accuracy are known to

*To whom correspondence should be addressed.

E-mail: rjvaarde@zoology.up.ac.za be affected by canopy cover and topography (Edenius 1997; Moen et al. 1997; D'Eon et al. 2002; Di Orio et al. 2003). Fix rate is often biased, with certain landscape properties hindering location calculation. This may reduce estimates of the use of certain habitat types by study animals (Di Orio et al. 2003; Lewis et al. 2007), especially during periods when animals take shelter in places where satellite reception is poor (Hays et al. 2001; Adrados et al. 2003; Bradshaw et al. 2007). Location bias driven by landscape properties may also affect estimates of home range area (Girard et al. 2002) and resource selection coefficients (Johnson \& Gillingham 2008), causing Type II errors, particularly when sampling intensity is high (Frair et al. 2004). Furthermore, Jerde \& Visscher (2005) demonstrate that estimates of turning angle and step length, as well as movement models inferred from locations, are accurate only when step lengths exceed measurement error.

A number of methods have been developed to improve location accuracy since the emergence of GPS telemetry. Contemporary methods focus on improving location accuracy, but introduce errors by changing the scale of the analysis, increasing variance through smaller sample sizes (Bradshaw 
et al. 2007), and affecting estimates of habitat use (Lewis et al. 2007). Such methods include filtering, sample weighting and iterative simulation (Dussault et al. 2001; Frair et al. 2004; O'Brien et al. 2006; Bradshaw et al. 2007; Lewis et al. 2007). Furthermore, despite the apparent increase in location accuracy through the application of these methods, data lost due to missing locations cannot be remedied because loss is usually non-random and related to habitat variables (Rettie \& McLoughlin 1999).

The large number of units deployed over the last decade reflects on the popularity of GPS telemetry. For instance, since 1999 a single supplier has assembled at least 800 collars for elephant (Loxodonta africana) studies in Africa (Sophie Haupt, pers. comm. Africa Wildlife Tracking CC, Pretoria, South Africa). These studies are often motivated by the conservation predicament of elephants and the need to deduce their movement patterns, evaluate habitat utilization patterns and study conflict between elephants and people (e.g. Grainger et al.2005; Leggett 2006; Wittemyer et al. 2007; Harris et al. 2008; Jackson et al. 2008; Blake et al. 2008). To our knowledge, there has been no formal attempt to evaluate the performance of units deployed on elephants in southern Africa. However, we know of at least 30 peer-reviewed papers that report on the performance of GPS telemetry elsewhere, almost all from studies in the northern hemisphere where such collars were deployed on cervids (Table 4). Cervids carry GPS-collars at $\sim 1 \mathrm{~m}$ above the ground, compared to elephants at $>2 \mathrm{~m}$. Furthermore, cervids travel across much smaller home ranges and distances than elephants. Fix rate is usually high for species living in open landscapes such as African savannas (95-97\% Douglas-Hamilton 1998), but lower for more closed habitats, including temperate and boreal forests (e.g. 69-90\% Dussault et al. 1999; 69-82\% Burdett et al. 2007).

We therefore opted to assess, 1) how landscape properties typical of savannas interfere with fix rate and accuracy and 2) how the exclusion of apparently less accurate 2D locations affects inferences of landscape utilization by elephants. To do this we first conducted trials to ascertain how fix rate and accuracy varied with landscape properties such as canopy cover and slope. We wanted to know how landscape properties influence i) fix rate, ii) the number of $2 \mathrm{D}$ and $3 \mathrm{D}$ locations recorded, iii) if $2 \mathrm{D}$ locations were more accurate than 3D locations, and iv) if the accuracy of the dataset im- proved significantly when 2D locations were excluded by filtering.

In a subsequent step, we tested the effect of filtering on inferences of landscape utilization using data from units deployed on 32 free-ranging elephants. Here we asked whether filtering i) disproportionately reduced the number of locations recorded in each canopy type, ii) increased calculated daily displacement distances, iii) changed calculated core range and home range areas (50\% and $90 \%$ Kernels, respectively), and iv) changed resource selection ratios.

\section{METHODS}

\section{Study area}

We conducted trials to assess the fix rate and accuracy of collars on the University of Pretoria's experimental farm in stands of natural vegetation with varying canopy cover and slope (Table 1). Data from free-ranging elephants at sites across southern Africa were used to assess effects of accuracy on estimates of home range and resource selection. To standardize protocol we used data from May and June 2006 because it falls within the dry season when the incidence of water vapour in the atmosphere that may interfere with GPS-satellite signals was minimal. At this time of the year, the deciduous trees typical of the region have not yet shed their leaves, so maintaining canopy cover typical of closed and open woodlands. Vegetation structure varied from areas with no canopy cover to closed woodlands (Table 1).

Our assessment was based on GPS telemetry collars assembled by Africa Wildlife Tracking CC, Pretoria, South Africa (model AWT MT 2000). These units employed a GPS receiver and a Vistar satellite unit to communicate with a geostationary satellite using external antennae (for technical details regarding Inmarsat's I-4 satellite, or the collar unit see http://www.inmarsat.com and http://www.awt.co.za, respectively). Locations were downloaded remotely via the internet and tracking software (MS Track Pro 8.0.1.6, (C) 19912007, Business Information Systems Ltd., Vermont, U.S.A.). Aside from location coordinates, date, and time, the units also recorded whether a location was based on 3D or 2D data. Our service provider did not supply information on the positional dilution of precision (PDOP) for each location.

\section{Stationary trials}

The five collars used here were retrieved from elephants tracked for two years as part of our 
Table 1. Description of the canopy and slope categories used for stationary trials and field data. The canopy categories were based on structural vegetation units classified from satellite imagery in study sites across southern Africa. The shrubland category was only applied to field data.

\begin{tabular}{lll}
\hline Trial & Category & Description \\
\hline Canopy & $\begin{array}{l}\text { No cover } \\
\text { Shrubland }\end{array}$ & $\begin{array}{l}\text { Open area with less than } 5 \% \text { canopy cover, either grassland or bare ground } \\
\text { Open area with less than } 5 \% \text { tree canopy cover, but more than } 30 \% \text { of the ground } \\
\text { covered by shrubs and small trees (only for field data) }\end{array}$ \\
& $\begin{array}{l}\text { Open woodland } \\
\text { Closed woodland }\end{array}$ & $\begin{array}{l}\text { Area with trees and shrubs covering less than } 60 \% \text { of the ground surface } \\
\text { Area with trees covering more than } 80 \% \text { of the ground surface }\end{array}$ \\
& $<5 \%$ & Flat to low gradient land surface that slopes less than $5 \%$ \\
& $>5-15 \%$ & Land surface slopes between 5 and $15 \%$ \\
& $>15-30 \%$ & A hillside where the land surface slopes between 15 and $30 \%$ \\
& A very steep slope with a gradient of more than $30 \%$
\end{tabular}

ongoing research programme. For the present study, we set the units to record locations at hourly intervals. We positioned each unit on a $2 \mathrm{~m}$ high custom-made platform to simulate its height while fitted on a collar to the neck of an elephant. Each of the collars were placed at a different site and each site represented one of three canopy cover categories and four slope categories to mimic field conditions (Table 1). All the sites for slope trials were in open woodland areas. The collars were moved to new pre-selected sites at least $500 \mathrm{~m}$ away from one another at 24 -hour intervals over a four-day period, yielding 15 and 20 sites for each of the cover and slope trials, respectively.

We used a differential GPS (Trimble Navigation Ltd, California, Model 4000ST GPS Surveyor), with a maximum horizontal and vertical accuracy of 1 and $2 \mathrm{~cm}$, respectively, to determine the position of each of the sites. We calculated the slope at each of the sites as a percentage (where $90^{\circ}$ to the horizontal $=100 \%$ ), using the altitude change and distance between two sites recorded with the differential GPS. For our analysis, we recognized four slope categories (Table 1).

We calculated fix rate for each cover and slope category as the number of locations recorded divided by the total expected, presented as a percentage (Lewis et al. 2007). This is equivalent to the term 'location success' as used by Moen et al. (1996). A chi-square test was used to determine whether fix rate differed between different canopy and slope categories. We also determined the incidence of $2 \mathrm{D}$ and $3 \mathrm{D}$ locations as a function of varying canopy cover and slope.

As a measure of location accuracy, we calculated the 50 and 95\% Circular Error Probable
(CEP) for unfiltered (2D \& 3D locations) and filtered (3D locations) data using the DNR Garmin extension (Minnesota Department of Natural Resources 2001) in ArcMap 9.2 $\left({ }^{\circ} \mathrm{ESRI}\right.$ Inc. 2006). To determine if CEP was significantly lower for filtered than for unfiltered data for canopy and slope trial categories, we used the Wilcoxon signed rank non-parametric $t$-test. We also used this test to assess the influence of canopy and slope categories on CEP for filtered and unfiltered data.

\section{Field data}

We extracted field locations from GPS units deployed on 32 free-ranging elephants that were collared and tracked for a two-year period in six conservation areas across southern Africa. The ethics committee of the University of Pretoria sanctioned the deployment of collars on elephants (permit number AUCC-040611-013). The GPS units recorded locations at 12-hour intervals throughout the two-year period. Using ArcMap 9.2, we superimposed locations onto classified landscape maps depicting canopy cover of each study site. We assessed the influence of filtering on the utilization of each vegetation type, daily displacement distances, Resource Selection Function (RSF) forage ratios as well as home range areas. We calculated the distance between successive daily locations. These are often referred to as step lengths (Jerde \& Visscher 2005; Bradshaw et al. 2007) and are useful in elephant habitat utilization studies at various temporal scales (Loarie et al. 2009; Young \& van Aarde 2010). The RSF forage ratio $\left(\hat{w}_{i}\right)$, an index of the probability of resource use by an organism, was calculated using the 
a

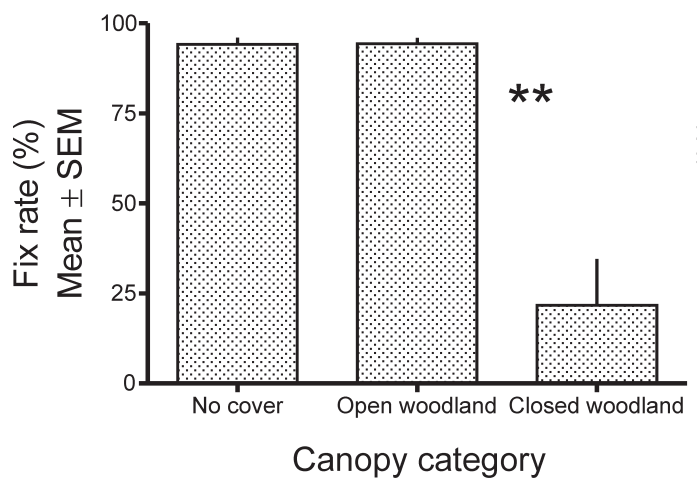

C

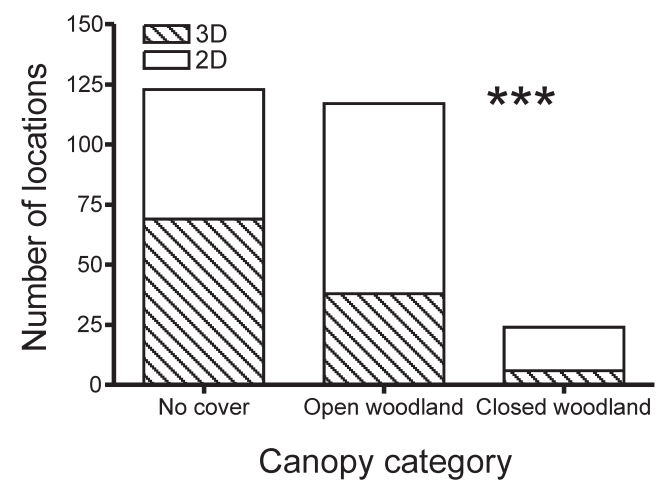

b

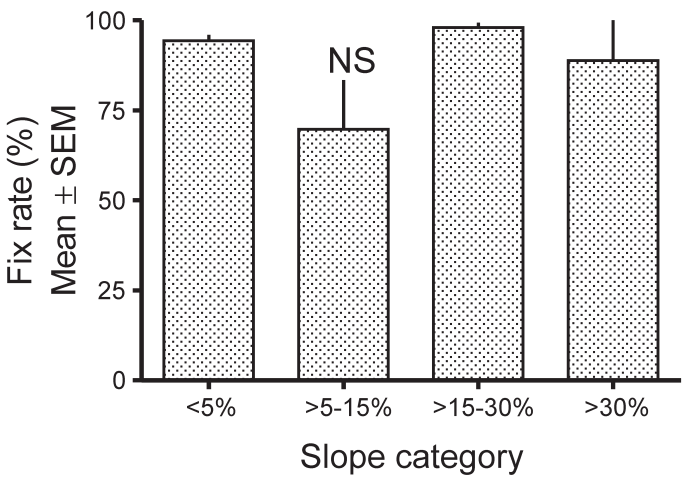

d

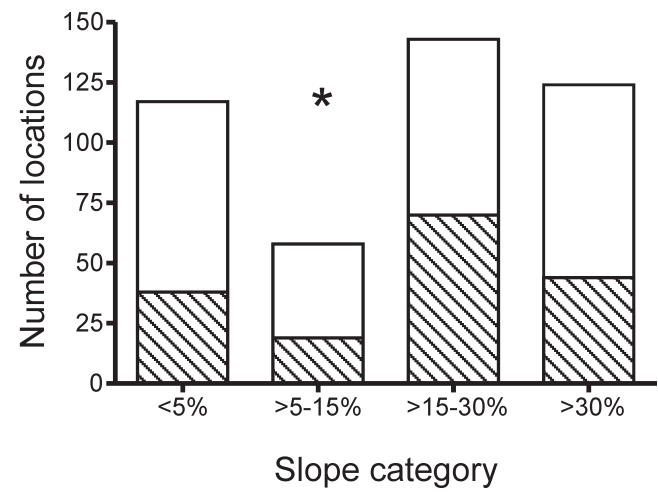

Fig. 1. Fix rate $(\mathbf{a} \& \mathbf{b})$ and the number of locations $(\mathbf{c} \& \mathbf{d})$ as a function of canopy cover and slope during stationary trials. Significant and non-significant differences are denoted by ${ }^{* *}$ and NS, respectively.

elephant locations and proportions of canopy categories for each study site (Manly et al. 2002). We calculated 50 and $90 \%$ fixed Kernel home ranges (Worton 1989) with the Animal Movement extension (Hooge \& Eichenlaub 1997) to ArcView GIS 3.3 ( ${ }^{\circ} \mathrm{ESRI}$ Inc. 2002). The outcomes of both filtered and unfiltered data for various spatial parameters were compared using the Wilcoxon signed rank test, chi-square test or sign test. We used these non-parametric tests because data did not satisfy the normality requirements of similar parametric tests.

\section{RESULTS}

\section{Locations from trials}

The GPS units recorded 706 locations during the trials, 264 and 442 locations for the canopy cover and slope trials, respectively. Fix rate was high (with an average of $70 \pm 38.8 \%$ (mean \pm S.D.) for canopy trials and $90 \pm 18.8 \%$ for slope trials), decreasing significantly with increased canopy cover (Kruskal-Wallis non-parametric test: $H=$ 9.78, $P=0.008$ and Dunn's post-hoc test, $P<$ 0.05 ), but was not a function of slope (KruskalWallis non-parametric test: $H=6.57, P=0.087$ ). The number of 2D locations removed by filtering increased significantly with increasing canopy cover $\left(2 \times 3\right.$ contingency table: $\chi^{2}=17.1, P=$ 0.0002 , see Fig. 1c) but only marginally with slope $\left(2 \times 4\right.$ contingency table: $\chi^{2}=9.65, P=0.022$, see Fig. 1d). We found that 2D locations were significantly less accurate than 3D locations at both the 50\% (Wilcoxon signed rank test: $W=$ 253.0, $P<0.0001$, Fig. 1e) and 95\% (Wilcoxon signed rank test: $W=253.0, P=0.0001$, Fig. 1f) Circular Error Probable (CEP). Therefore, the exclusion of 2D locations significantly improved location accuracy at both the 50 and 95\% CEP under various canopy (Wilcoxon signed rank test: $W=36.0, P=0.008$ and $W=45.0, P=0.004$, respectively), and slope categories (Wilcoxon 

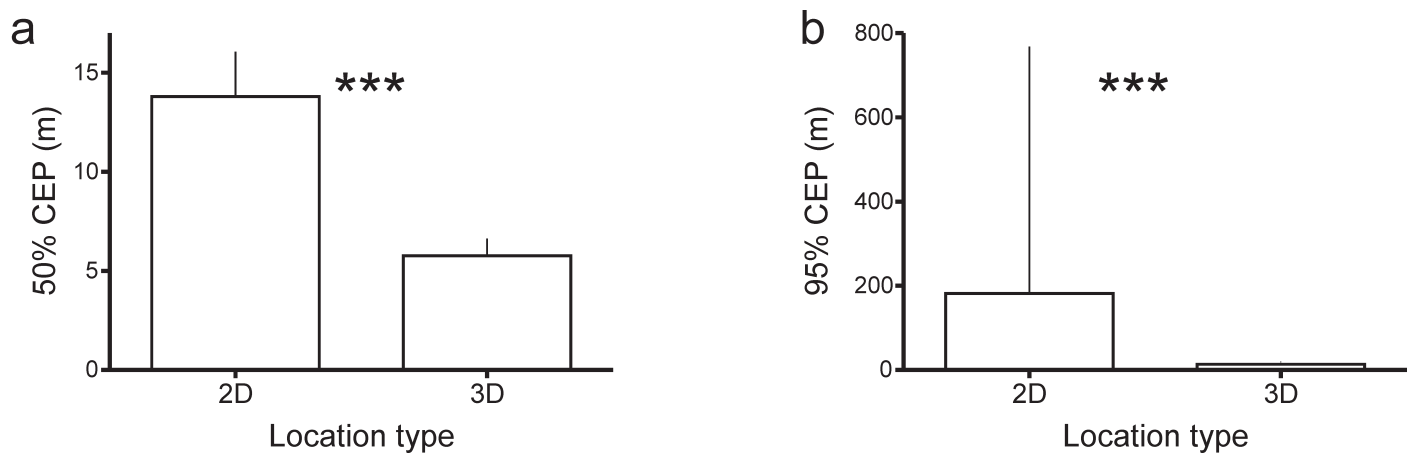

Fig. 2. The $50 \%$ (a) and 95\% (b) Circular Error Probable (CEP) as functions of location type during stationary trials. Significant differences are denoted by ${ }^{* * *}$.

signed rank test: $W=153.0, P=0.0003$ and $W=$ 171.0, $P=0.0002$, respectively).

\section{Locations from free-ranging elephants}

Fix rate was high (between 88 and $96 \%$ ) for the 3589 locations downloaded for a two-month period (May and June 2006) from 32 collars deployed on free-ranging elephants across southern Africa. Fix rate did not differ between sites $(2 \times 6$ contingency table: $\chi^{2}=7.41$, d.f. $=5, P=0.192$ ). . However, based on pooled data, the number of locations per canopy category was significantly reduced by filtering $\left(2 \times 4\right.$ contingency table: $\chi^{2}=23.78$, d.f. $=3, P<$ 0.0001 ), where between 30 and $50 \%$ of locations were lost through filtering (Fig. 2a). The values reported here for fix rate (trials and field data), as well as accuracy (trials), are within the range of those of other studies that assess GPS units from several other manufacturers (see Table 2).

Daily displacement distances were significantly longer when 2D locations were excluded ( $W=$ 3.44, $P=0.0006$, Fig. 2b). For two elephants, only $2 \mathrm{D}$ locations were recorded, thus making it impossible to estimate home range sizes for these animals using 3D (filtered) data (Fig. 2c \& 2d). These two cases were therefore excluded from further analyses. The sign test revealed that unfiltered location data returned larger Kernel home range areas than filtered data. However, for both the 50 and $90 \%$ Kernel home ranges, these differences were not statistically significant with only $63 \%$ (sign test: $Z=1.28, P=0.201$, Fig. $2 \mathrm{e}$ ) and $70 \%$ (sign test: $Z=2.01, P=0.045$, Fig. 2 d) of unfiltered home ranges being larger than filtered home ranges, respectively. Forage ratios were similarly unaffected by filtering (sign test: $Z=0.00$, $P=1.000$, Fig. 2 d), $48 \%$ of unfiltered ratios were larger than filtered ratios.

\section{DISCUSSION}

Inaccuracies induced by technical limitations and landscape properties should be considered when inferring patterns of landscape utilization from GPS telemetry (Bradshaw et al. 2007; Lewis et al. 2007). Consequently, several procedures have been developed to address location accuracy (e.g. Rettie \& Mcloughlin 1999; Frair et al. 2004; Hebblewhite et al. 2007). The exclusion of less accurate 2D locations (e.g. Lewis et al. 2007), reduces sampling effort and may therefore weaken statistical inferences of spatial utilization patterns (Frair et al. 2004). Landscape properties such as slope and canopy cover are known to reduce fix rate as well as accuracy (e.g. Di Orio et al. 2003; Cain et al. 2005; Bradshaw et al. 2007; Zweifel-Schielly \& Suter 2007; Hansen \& Riggs 2008) but these effects are seldom if ever considered in GPS telemetry studies in southern Africa. We therefore addressed some of the consequences of landscape properties on location data recorded by GPS-units deployed on elephants across southern Africa.

In our trials, fix rate was lowest in closed woodlands but unaffected by slope, as has also been noted by others (Di Orio et al. 2003; Frair et al. 2004; Lewis et al. 2007; Zweifel-Schielly \& Suter 2007; Hansen \& Riggs 2008). These observations however, differ from those of Cain et al. (2005) and of Hebblewhite et al. (2007), who illustrate that rugged topography reduces fix rate. Different to ours, their studies took place in mountains rather than rocky outcrops like those of our study area. Hebblewhite et al. (2007) show that collars on steep slopes have better satellite coverage than those on shallow slopes and this may explain why we recorded higher accuracies on steep slopes. We did not evaluate the interaction between 
Ott \& Van Aarde: Spatial use by elephants is robust to landscape effects on GPS telemetry

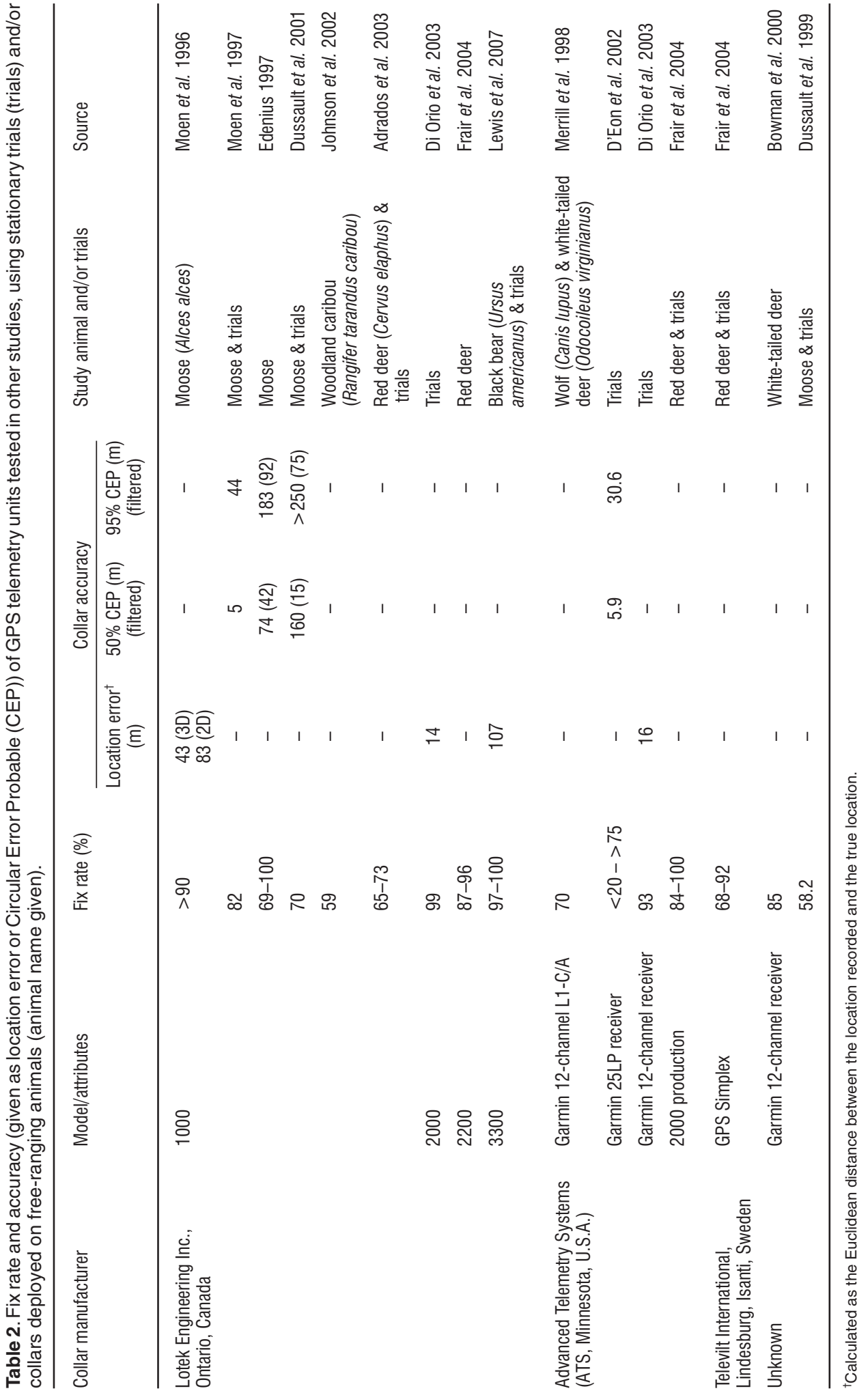


a

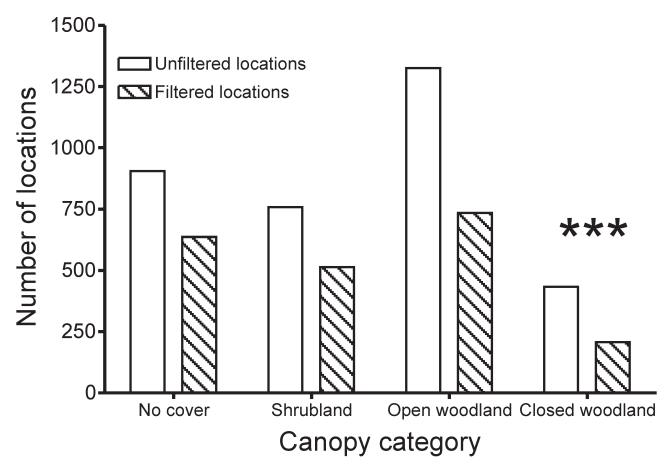

C

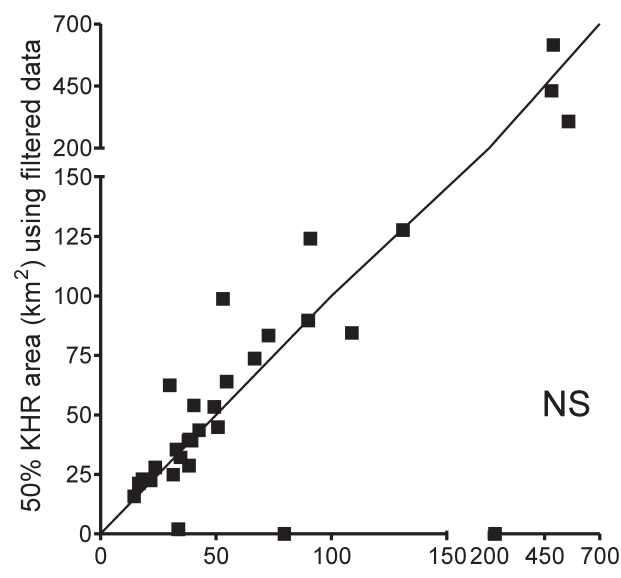

$50 \% \mathrm{KHR}$ area $\left(\mathrm{km}^{2}\right)$ using unfiltered data

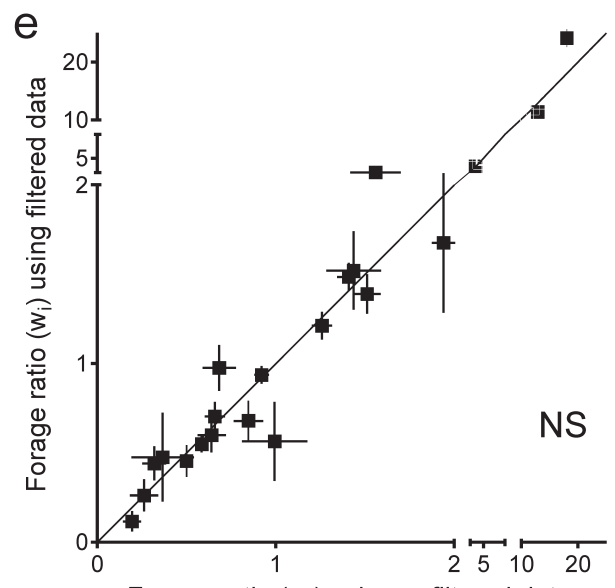

Forage ratio $\left(w_{i}\right)$ using unfiltered data b

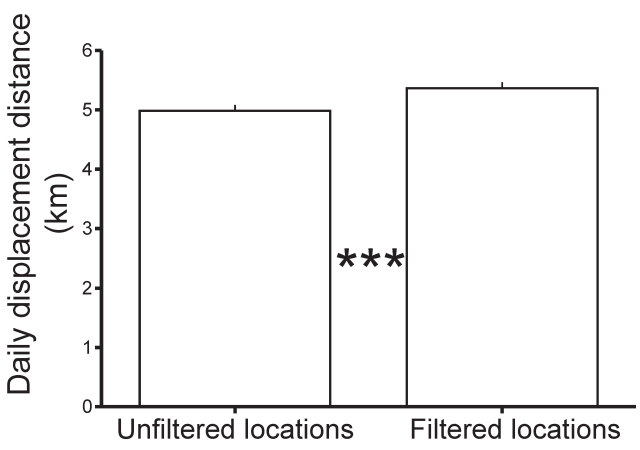

d

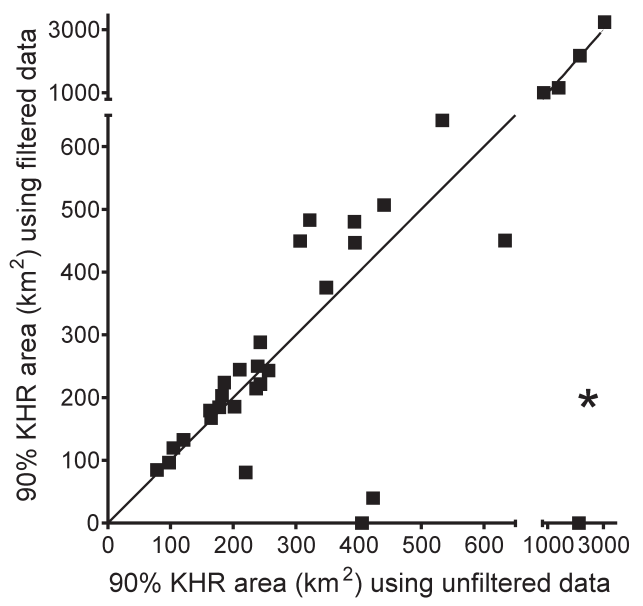

Fig. 3. The effect of the exclusion of $2 \mathrm{D}$ locations on inferences on elephant spatial utilization: $\mathbf{a}$, the number of locations recorded in different canopy categories; b, daily displacement distances; c \& d, estimates of Kernel home range sizes; $\mathbf{e}$, Resource Selection Function (RSF) forage ratios. The diagonal line (c-e) represents a one-to-one line where the differences between effects on variables calculated with $2 \mathrm{D}+3 \mathrm{D}$ and $3 \mathrm{D}$ would be zero. The horizontal and vertical lines indicate the standard error of the mean for the 3D $+2 \mathrm{D}$ and $3 \mathrm{D}$ selection ratios for elephants within each park, respectively. Significant and non-significant differences are denoted by ${ }^{* *}$ and NS, respectively. 
canopy cover and slope, but Frair et al. (2004) suggest that slope may interact with canopy cover to further reduce fix rate.

Similar to Douglas-Hamilton (1998), we showed that fix rate of units on free-ranging elephants was greater than that assessed during stationary trials. This differs from other studies where fix rates for units on free-ranging animals returned fewer locations than those of stationary trials, probably due to animals sheltering in sites where terrain reduced satellite reception (Edenius 1997; Bowman et al. 2000; Zweifel-Schielly \& Sute, 2007). We assume that this difference stems from the relatively high fix rate in habitats with relatively low canopy cover, where elephants may spend most of their time. It is also possible that leaf density of the closed woodland category locations that we used for our trials was greater than that typical of the elephant study sites, thus reducing fix rates. However, fix rate was within the range of that reported by others for free-ranging cervids (e.g. Edenius 1997; Moen et al. 1997; Dussault et al. 2001; Adrados et al. 2003; Frair et al. 2004).

In our study, 2D locations were, as elsewhere, less accurate than 3D locations and their exclusion therefore improved accuracy (e.g. Lewis et al. 2007). However, filtering of both trial and field locations, reduced data substantially, as was shown by others (e.g. D'Eon \& Delparte 2005; Lewis et al.2007), and affected some inferences of elephant landscape utilization. The exclusion of $2 \mathrm{D}$ locations from field data disproportionately reduced the number of locations per canopy type and increased daily displacement distances. This may argue in favour of the inclusion of $2 \mathrm{D}$ locations in such analyses, especially because estimates of distances between locations are accurate when they are large relative to measurement error (Jerde \& Visscher 2005), as was the case in our study.

Filtering had no effect on the RSF forage ratios that we estimated for elephants across southern Africa. Frair et al. (2004) as well as Johnson \& Gillingham (2008) however noted that RSF model coefficients are sensitive to location error and Frair et al. (2004) suggest that this was due to type II errors caused by data loss. The different RSF approaches used in studies detract from comparisons of the consequences of filtering and we suggest that this requires further study.

For elephants, filtered and unfiltered data produced similar 50 and $90 \%$ Kernel home-range area estimates. This agrees with Rettie \&
McLoughlin (1999), who also suggest that the effects of error may be reduced by buffers or polygons constructed around locations or sets of locations. Again though, we noted that the exclusion of 2D locations caused the complete removal of the data of two elephants. Bearing these points in mind it seems unnecessary to filter data when estimating Kernel home ranges.

When considering that the removal of relatively inaccurate data through the exclusion of $2 \mathrm{D}$ locations had little effect on estimates of resource selection and home range sizes, but dramatically reduced sample sizes, we posit that such filtering should not be applied in studies on spatial utilization of free-ranging elephants and possibly other megaherbivores. However, for species that roam over relatively short distances between locations, filtering may be necessary for inferences of spatial utilization to be drawn.

\section{ACKNOWLEDGEMENTS}

Conservation International, Conservation Foundation Zambia, the International Fund for Animal Welfare, the Peace Parks Foundation, and the University of Pretoria financially supported the study. We would like to thank J. Esterhuizen of the Geography Department at the University of Pretoria who assisted with the use of the differential GPS during the stationary trials.

\section{REFERENCES}

ADRADOS, C., VERHEYDEN-TIXIER, H., CARGNELUTTI, B., PÉPIN, D. \& JANEAU, G. 2003. GPS approach to study fine-scale site use by wild red deer during active and inactive behaviours. Wildlife Biol. 31: 544-553.

BLAKE, S., DEEM, S.L., STRINDBERG, S., MAISELS, F., MOMONT, L., ISIA, I., DOUGLAS-HAMILTON, I., KARESH, W.B. \& KOCK, M.D. 2008. Roadless wilderness area determines forest elephant movements in the Congo Basin. PLOS ONE 3: 1-9.

BOWMAN, J.L., KOCHANNY, C.O., DEMARAIS, S. \& LEOPOLD, B.D. 2000. Evaluation of a GPS collar for white-tailed deer. Wildlife Soc. B. 28: 141-145.

BRADSHAW, C.J.A., SIMS, D.W. \& HAYS, G.C. 2007. Measurement error causes scale-dependent threshold erosion of biological signals in animal movement data. Ecol. Appl. 17: 628-638.

BURDETT, C.L., MOEN, R.A., NIEMI, G.J. \& MECH, L.D. 2007. Defining space use and movements of Canada lynx with global positioning system telemetry. J. Mammal. 88: 457-467.

CAIN, J.W., KRAUSMAN, P.R., JANSEN, B.D. \& MORGART, J.R. 2005. Influence of topography and GPS fix interval on GPS collar performance. Wildlife Soc. B. 33: 926-934.

D'EON, R.G. \& DELPARTE, D. 2005. Effects of radiocollar position and orientation on GPS radio-collar 
performance, and the implications of PDOP in data screening. J. Appl. Ecol. 42: 383-388.

D'EON, R.G., SERROUYA, R., SMITH, G. \& KOCHANNY, C.O. 2002. GPS radiotelemetry error and bias in mountainous terrain. Wildlife Soc. B. 30: 430-439.

DI ORIO, A.P., CALLAS, R. \& SCHAEFER, R.J. 2003. Performance of two GPS telemetry collars under different habitat conditions. Wildlife Soc. B. 31: 372-379.

DOUGLAS-HAMILTON, I. 1998. Tracking African elephants with a global positioning system (GPS) radio collar. Pachyderm 25: 82-91.

DUSSAULT, C., COURTOIS, R., OUELLET, J-P. \& HUOT, J. 1999. Evaluation of GPS telemetry collar performance for habitat studies in the boreal forest. Wildlife Soc. B. 27: 965-972.

DUSSAULT, C., COURTOIS, R., OUELLET, J-P. \& HUOT, J. 2001. Influence of satellite geometry and differential correction on GPS location accuracy. Wildlife Soc. B. 29: 171-179.

EDENIUS, L. 1997. Field test of a GPS location system for moose Alces alces under Scandinavian boreal conditions. Wildlife Biol. 3: 39-43.

FRAIR, J.L., NIELSEN, S.E., MERRILL, E.H., LELE, S.R., BOYCE, M.S., MUNRO, R.H.M., STENHOUSE, G.B. \& BEYER, H.L. 2004. Removing GPS collar bias in habitat selection studies. J. Appl. Ecol. 41: 201-212.

GIRARD, I., OUELLET, J-P., COURTOIS, R., DUSSAULT, C. \& BRETON, L. 2002. Effects of sampling effort based on GPS telemetry on home-range size estimations. J. Wildlife Manage. 66: 1290-1300.

GRAINGER, M., VAN AARDE, R.J. \& WHYTE, I. 2005. Landscape heterogeneity and the use of space by elephants in Kruger National Park, South Africa. Afr. J. Ecol. 43: 369-375.

HANSEN, M.C. \& RIGGS, R.A. 2008. Accuracy, precision and observation rates of global positioning system telemetry collars. J. Wildlife Manage. 72: 518-526.

HARRIS, G.M., RUSSELL, G.J., VAN AARDE, R.J. \& PIMM, S.L. 2008. Rules of habitat use by elephants Loxodonta africana in southern Africa: insights for regional management. Oryx 42: 66-75.

HAYS, G.C., AKESSON, S., GODLEY, B.J., LUSCHI, P. \& SANTIDRIAN, P. 2001. The implications of location accuracy for the interpretation of satellite-tracking data. Anim. Behav. 61: 1035-1040.

HEBBLEWHITE, M., PERCY, M. \& MERRILL, E.H. 2007. Are all global positioning system collars created equal? Correcting habitat-induced bias using three brands in the Central Canadian Rockies. J. Wildlife Manage. 71: 2026-2033.

HOOGE, P.N. \& EICHENLAUB, B. 1997. Animal movement extension to ArcView. (1.1). Alaska Science Center - Biological Science Office, U.S. Geological Survey, Anchorage.

JACKSON, T.P., MOSOJANE, S., FERREIRA, S. \& VAN AARDE, R.J. 2008. Solutions for elephant crop raiding in northern Botswana: moving away from symptomatic approaches. Oryx 42: 83-91.
JERDE, C.L. \& VISSCHER, D.R. 2005. GPS measurement error influences on movement model parameterization. Ecol. Appl. 15: 806-810.

JOHNSON, C.J. \& GILLINGHAM, M. 2008. Sensitivity of species-distribution models to error, bias and model design: an application to resource selection functions for woodland caribou. Ecol. Model. 213: 143-155.

JOHNSON, C.J., HEARD, D.C. \& PARKER, K.L. 2002. Expectations and realities of GPS animal location collars: results of three years in the field. Wildlife Biol. 8: 153-159.

LEGGETT, K.E.A. 2006. Home range and seasonal movement of elephants in the Kunene Region, northwestern Namibia. Afr. Zool. 41: 17-36.

LEWIS, J.S., RACHLOW, J.L., GARTON, E.O. \& VIERLING, L.A. 2007. Effects of habitat on GPS collar performance: using data screening to reduce location error. J. Appl. Ecol. 44: 663-671.

LOARIE, S.R., VAN AARDE, R.J. \& PIMM, S.L. 2009. Elephant seasonal vegetation preferences across dry and wet savannas. Biol. Conserv. 142: 3099-3107.

MANLY, B.F.J., McDONALD, L.L., THOMAS, D.L., McDONALD, T.L. \& ERICKSON, W.P. 2002. Resource selection by animals. Kluwer Academic Publishers, Dordrecht.

MERRILL, S.B., ADAMS, L.G., NELSON, M.E. \& MECH, L.D. 1998. Testing releasable GPS radiocollars on wolves and white-tailed deer. Wildlife Soc. B. 26 : 830-835.

MOEN, R., PASTOR, J., COHEN, Y. \& SCHWARTZ, C.C. 1996. Effects of moose movement and habitat use on GPS collar performance. J. Wildlife Manage. 60: 659-668.

MOEN, R., PASTOR, J. \& COHEN, Y. 1997. Accuracy of GPS telemetry collar locations with differential correction. J. Wildlife Manage. 61: 530-539.

O'BRIEN, D., MANSEAU, M., FALL, A. \& FORTIN, M.J. 2006. Testing the importance of spatial configuration of winter habitat for woodland caribou: an application of graph theory. Biol. Conserv. 130: 70-83.

RETTIE, W.J. \& McLOUGHLIN, P.D. 1999. Overcoming radiotelemetry bias in habitat-selection studies. Can. J. Zool. 77: 1175 .

WITTEMYER, G., GETZ, W.M., VOLLRATH, F. \& DOUGLAS-HAMILTON, I. 2007. Social dominance, seasonal movements, and spatial segregation in African elephants: a contribution to conservation behaviour. Behav. Ecol. Sociobiol. 61: 1919-1931.

WORTON, B.J. 1989. Kernel methods for estimating the utilisation distribution in home-range studies. Ecology 70: 164-168.

YOUNG, K.D. \& VAN AARDE, R.J. 2010. Density as an explanatory variable of movements and calf survival in savanna elephants across southern Africa. J. Anim. Ecol. 79: 662-673.

ZWEIFEL-SCHIELLY, B. \& SUTER, W. 2007. Performance of GPS telemetry collars for red deer Cervus elaphus in rugged Alpine terrain under controlled and free-living conditions. Wildlife Biol. 13: 299-312. 